\title{
Prognostic factors of pediatric hematopoietic stem cell transplantation recipients admitted to the pediatric intensive care unit
}

\author{
Da Hyun Kim, Eun Ju Ha, Seong Jong Park, Kyung-Nam Koh, Hyery Kim, Ho Joon Im, Won Kyoung Jhang
}

Department of Pediatrics, Asan Medical Center Children's Hospital, University of Ulsan College of Medicine, Seoul, Korea

Background: Pediatric patients who received hematopoietic stem cell transplantation (HSCT) tend to have high morbidity and mortality. While, the prognostic factors of adult patients received bone marrow transplantation were already known, there is little known in pediatric pateints. This study aimed to identify the prognostic factor for pediatric intensive care unit (PICU) mortality of critically ill pediatric patients with HSCT.

Methods: Retrospectively reviewed that the medical records of patients who received HSCT and admitted to PICU between January 2010 and December 2019. Mortality was defined a patient who expired within 28 days.

Results: A total of 131 patients were included. There were 63 boys (48.1\%) and median age was 11 years (interquartile range, 4-15 years). The most common HSCT type was haploidentical (38.9\%) and respiratory failure (44.3\%) was the most common reason for PICU admission. Twenty-eightday mortality was $22.1 \%$ (29/131). In comparison between survivors and non-survivors, the number of HSCTs received, sepsis, oncological pediatric risk of mortality-III (OPRISM-III), pediatric risk of mortality-III (PRISM-III), pediatric Sequential Organ Failure Assessment (pSOFA), serum lactate, B-type natriuretic peptide (BNP) and use of mechanical ventilator (MV) and vasoactive inotropics were significant predictors ( $\mathrm{P}<0.05$ for all variables). In multivariate logistic regression, the number of HSCTs received, use of MV, OPRISM-III, PRISM-III and pSOFA were independent risk factors of PICU mortality. Moreover, three scoring systems were significant prognostic factors of 28-day mortality.

Conclusions: The number of HSCTs received and use of MV were more accurate predictors in pediatric patients received HSCT.

Key Words: hematopoietic stem cell transplantation; mortality; pediatric intensive care unit; prognosis

\section{INTRODUCTION}

Hematopoietic stem cell transplantation (HSCT) is currently used as a treatment for highrisk or relapsed hematologic malignancies and non-malignant hematologic disease [1,2]. For successful transplantation, recipients have to overcome several complications such as sepsis, graft versus host disease (GVHD), thrombotic microangiopathies, and veno-occlusive

\section{Original Article}

Received: January 8, 2021

Revised: August 5, 2021

Accepted: August 30, 2021

\section{Corresponding author}

Won Kyoung Jhang

Division of Pediatric Critical Care

Medicine, Department of Pediatrics, Asan Medical Center Children's

Hospital, University of Ulsan College of Medicine, 88 Olympic-ro 43-gil, Songpa-gu, Seoul 05505, Korea

Tel: +82-2-3010-5936

Fax: +82-2-3010-6978

E-mail:wkjhang@amc.seoul.kr

Copyright (C) 2021 The Korean Society of Critical Care Medicine

This is an Open Access article distributed under the terms of Creative Attributions Non-Commercial License (https:// creativecommons.org/li-censes/by-nc/4.0/) which permits unrestricted noncommercial use, distribution, and reproduction in any medium, provided the original work is properly cited. 
disease that occur after HSCT [3-5]. To prevent complications, the HSCT protocol has been reorganized across areas such as precise human leukocyte antigen (HLA) typing, graft manipulation, conditioning regimen, prophylactic antibiotics, or antifungal agents [5-8]. Also, intensive care management has been improved with time [9]. However, a significant proportion of adult and pediatric recipients still become critically ill, requiring admission to the intensive care unit (ICU). Many factors, including preexisting disease, transplant-related toxicity, infection, and sequelae of pre- or post-transplant organ damage, are thought to be contributory.

As the number of HSCTs patients increases, the number of patients admitted to the ICU also increases. Thus, many investigators are working on identifying the prognostic factors of ICU mortality. Several HSCT-related factors, such as underlying disease, type of HLA mismatch, failure of neutrophil engraftment, presence of GVHD, and cytomegalovirus (CMV) seropositivity are associated with increased mortality after HSCT [10-12]. Critical care interventions, such as mechanical ventilator (MV), renal replacement therapy, vasoactive inotropes were known to be the significant factors of mortality [13]. Moreover, many studies have assessed the correlation between scoring systems, such as the Acute Physiology and Chronic Health Evaluation (APACHE) II, Simplified Acute Physiology Score (SAPS), and Sequential Organ Failure Assessment (SOFA) scores, and mortality in adults $[11,14]$. However, for pediatric patients, only a few such studies have assessed the severity of illness in HSCT patients as a prognostic factor, and there are only a few studies on the reappraisal of pediatric HSCT recipients. Pedaitric HSCT patients have increased severity in a variety of forms when they admit pediatric intensive care unit (PICU) and the prognostic factors resulting from mortality have been also rarely studied. Thus, we reviewed that the critical ill pediatric patients admitted to the ICU to identify the significant risk factors, especially severity illness of scores, which can predict mortality.

\section{MATERIALS AND METHODS}

\section{Patients}

We investigated all HSCT recipients admitted to the 14-bed multidisciplinary PICU of Asan Medical Center Children's Hospital, Seoul, Korea between January 2010 and December 2019. We excluded patients who had insufficient data necessary for severity scoring and patients with a Do-Not-Resuscitate order in place. The Institutional Review Board of

\section{KEYMESSAGES}

- Pediatric patients who received hematopoietic stem cell transplantation (HSCT) tend to have several complications and have high mortality.

- The number of HSCTs received, use of mechanical ventilator, oncological pediatric risk of mortality-III (OPRISMIII), pediatric risk of mortality-III (PRISM-III), and pediatric Sequential Organ Failure Assessment (pSOFA) were significant prognostic factor of 28-day mortality.

the Asan Medical Center approved this study (IRB No. 20200382) and parental consent was waived due to the retrospective nature of the analyses.

\section{Data Collection}

We retrospectively reviewed the electrical medical records of the enrolled patients and obtained data, including age at PICU admission, sex, underlying hemato-oncologic disease, length of PICU stay, and mortality. The HSCT parameters, including HSCT type, development of acute GVHD, CMV infection, veno-occlusive disease, and transplant-associated thrombotic microangiopathy were evaluated. The clinical and biological variables, including vital signs, arterial blood gas analysis, and laboratory results, such as complete blood count, chemistry profiles, coagulation profiles, and C-reactive protein, serum lactic acid, and B-type natriuretic peptide (BNP) levels were analyzed. For identifying the severity of disease, we used the oncological pediatric risk of mortality-III (OPRISM-III), pediatric risk of mortality-III (PRISM-III), and pediatric Sequential Organ Failure Assessment (pSOFA) scores calculated within 24 hours of PICU admission. The PRISM-III consists of cardiovascular/neurologic vital signs, acid-base/blood gas values, and chemical (glucose, creatinine, potassium, and blood urea nitrogen), and hematologic laboratory values (white blood cell count, platelet count, and coagulation profile) [15]. The pSOFA comprises the ratio of the partial pressure of arterial oxygen to the fraction of inspired oxygen $\left(\mathrm{PaO}_{2} / \mathrm{FiO}_{2}\right)$ ratio, platelet count, bilirubin level, mean arterial pressure (MAP) or vasoactive infusion, Glasgow coma scale (GCS) score, and creatinine level [16]. The PRISM-III and pSOFA were often used to evaluate multiorgan failure in critically-ill pediatric patients, and the OPRISM-III, a modification of the PRISM-III, was used for assessing children after HSCT [17]. During ICU management, the need for invasive MV, continuous renal replacement therapy, and vasoactive inotropic drugs were monitored. Mortality was 
defined as a patient who died within 28 days during the PICU stay. The primary outcome was the PICU 28-days mortality and the secondary outcome was risk factors that predisposed to mortality.

\section{Statistical Analysis}

All data were analyzed using the IBM SPSS ver. 21.0 (IBM
Corp., Armonk, NY, USA). Continuous variables were summarized as median with interquartile range or mean \pm standard deviation and a two-tailed Student t-test, as appropriate. We used the chi-square or two-tailed Fisher's exact tests to analyze categorical variables. We used the multivariate logistic regression analysis to interrogate variables to find independent risk factors. We calculated the area under the curve (AUC) and the

Table 1. Baseline characteristics of the study population

\begin{tabular}{|c|c|c|c|c|}
\hline Variable & Total $(n=131)$ & Survivor $(n=102)$ & Non-survivor $(n=29)$ & P-value \\
\hline Male & $63(48.1)$ & $50(49)$ & $13(44.8)$ & 0.690 \\
\hline Age at HSCT & $9.46(3.14-14.79)$ & $9.54(2.63-14.84)$ & $9.46(3.26-15.42)$ & 0.939 \\
\hline Age at PICU admission & $11.00(4.00-15.00)$ & $11.00(4.00-25.00)$ & $9.00(3.00-15.00)$ & 0.233 \\
\hline Length of PICU stay (day) & $16.94 \pm 27.43$ & $19.54 \pm 30.34$ & $7.79 \pm 7.87$ & 0.041 \\
\hline Underlying hemato-oncologic disease & & & & 0.731 \\
\hline Leukemia & $67(51.1)$ & $53(52)$ & $14(48.3)$ & \\
\hline Lymphoma & $7(5.3)$ & $6(5.9)$ & $1(3.4)$ & \\
\hline Non-malignant hematologic disease & 26 (19.8) & $21(20.6)$ & $5(17.2)$ & \\
\hline Solid tumor & $31(23.7)$ & $22(21.6)$ & $9(31)$ & \\
\hline Types of donor & & & & 0.160 \\
\hline HLA matched (related) & $9(6.9)$ & $9(8.8)$ & $2(6.9)$ & \\
\hline HLA matched (unrelated) & $37(28)$ & $31(30.4)$ & $4(13.8)$ & \\
\hline HLA mismatched (related) & $53(40.4)$ & $35(34.3)$ & $16(55.2)$ & \\
\hline HLA mismatched (unrelated) & $5(3.8)$ & $5(4.9)$ & 0 & \\
\hline Autologous & $27(20.6)$ & $20(19.6)$ & $7(24.1)$ & \\
\hline No. of HSCTs & & & & 0.013 \\
\hline 1 & $106(80.9)$ & $88(86.3)$ & $18(62.1)$ & \\
\hline$\geq 2$ & $25(19.1)$ & $14(13.7)$ & $11(37.9)$ & \\
\hline Day from HSCT to admission & & & & 0.064 \\
\hline$<30$ & $21(16.0)$ & $14(13.7)$ & $7(24.1)$ & \\
\hline $31-99$ & $23(17.6)$ & $15(14.7)$ & $8(27.6)$ & \\
\hline$>100$ & 87 (66.4) & 73 (71.6) & 14 (48.3) & \\
\hline Main reason for PICU admission & & & & 0.460 \\
\hline Respiratory failure & $58(44.3)$ & $45(44.1)$ & $13(44.8)$ & \\
\hline Neurologic defect & 18 (13.7) & $12(11.8)$ & $6(20.7)$ & \\
\hline Sepsis & $17(13.0)$ & $13(12.7)$ & $4(13.8)$ & \\
\hline Renal failure & $12(9.2)$ & $10(9.8)$ & $2(6.9)$ & \\
\hline Hemato-oncology complication & $12(9.2)$ & $10(9.8)$ & $2(6.9)$ & \\
\hline Cardiovascular disease & $7(5.3)$ & $7(6.9)$ & 0 & \\
\hline Gastro-intestinal disease & $7(5.3)$ & $5(4.9)$ & $2(6.9)$ & \\
\hline CMV infection & $35(26.7)$ & $29(28.4)$ & $6(20.7)$ & 0.406 \\
\hline Veno-occlusive disease & $9(6.9)$ & $7(6.9)$ & $2(6.9)$ & 0.995 \\
\hline Graft-versus-host disease & $28(21)$ & $18(17.6)$ & $10(34.5)$ & 0.135 \\
\hline TA-TMA & $13(9.9)$ & $11(10.8)$ & $2(6.9)$ & 0.537 \\
\hline Septic shock & $17(13.0)$ & $13(12.7)$ & $4(13.8)$ & 0.022 \\
\hline
\end{tabular}

Values are presented as number (\%), median (interquartile range), or mean \pm standard deviation.

HSCT: hematopoietic stem cell transplantation; PICU: pediatric intensive care unit; HLA: human leukocyte antigen; CMV: cytomegalovirus; TA-TMA: transplantassociated thrombotic microangiopathy. 
DeLong test was used to compare the performance between two assays based on the AUC of receiver operating characteristics (ROC) curves. We obtained appropriate cut-off values and analyzed data according to the maximum value of the Youden index. Survival curves were performed using the Kaplan-Meier methodology and the log-rank test was used to compare variables. All variables with a P-value of less than 0.05 were considered statistically significant.

\section{RESULTS}

\section{Patients}

A total of 2858 children were admitted to the PICU from 2010 to 2019 , and 131 received HSCT. The demographic characteristics of the patients are presented in Table 1. There were 63 boys (48.1\%), and the median age of the patients admitted to the PICU was 11 years (interquartile range, 4-15 years). The most common underlying hemato-oncologic diagnosis was leukemia ( $\mathrm{n}=67,51.1 \%)$. A total of $104(79.4 \%)$ allogeneic and 27 (20.6\%) autologous bone marrow transplantation (BMT) procedures were performed. The median period from HSCT to admission was $197 \pm 84$ days (0-3,658 days). The period from HSCT to admission was more than 100 days for $66.4 \%$ of the patients; $30-99$ days, $17.6 \%$ and $<30$ days, $16 \%$. The most commonly noted reasons for PICU admission was respiratory failure ( $\mathrm{n}=58,44.3 \%)$, followed by neurologic defects $(\mathrm{n}=18$, $13.7 \%)$ and sepsis ( $\mathrm{n}=17,13.0 \%)$.

\section{Demographics and Comparisons between Survivors and Non-survivors}

The 28-day mortality rate was $22.1 \%(29 / 131)$. With respect to the baseline characteristics, the number of BMT and presence of septic shock were the significant factors affecting mortality ( $\mathrm{P}=0.013$ and $\mathrm{P}=0.031$, respectively) (Table 1). As shown in Table 2, the severity of illness scores (OPRISM-III, PRISM-III, and pSOFA) and several laboratory values (serum lactic acid, and BNP level) at PICU admission were the significant prognostic factors. In terms of treatments administered within the first day of PICU admission, the use of MV and vasopressors was associated with mortality $(\mathrm{P}=0.011$ and $\mathrm{P}=0.042$, respectively).

\section{Multivariate Logistic Regression Analysis}

The result of univariate logistic regression was the same as the result of the comparison between survivors and non-survivors. However, in multivariate analysis adjusted for other potentially confounding independent variables, the number of HSCTs received $(\mathrm{P}<0.05)$, use of MV $(\mathrm{P}<0.05)$, OPRISM-III (odds ratio [OR], 1.137; 95\% conficdence interval [CI], 1.0741.204; $\mathrm{P}<0.001)$, PRISM-III (OR, 1.144; 95\% CI, 1.0771.215; $\mathrm{P}<0.001$ ) and pSOFA (OR, 1.222; 95\% CI, 1.078-1.385; $\mathrm{P}=0.002$ ) were independent predictors of PICU mortality in separate logistic equations (Table 3 ).

\section{ROC Curve and Kaplan-Meier Analysis}

We found that the value of the area under the ROC (AUROC) curve of the three severity of illness scores were all associated

Table 2. Laboratory values, severity of illness scores, and treatment on the first day of PICU

\begin{tabular}{lcccc}
\hline Variable & Total $(n=131)$ & Survivor $(n=102)$ & Non-survivor $(n=29)$ & P-value \\
\hline OPRISM-III & $21.15 \pm 10.97$ & $18.23 \pm 8.76$ & $31.45 \pm 11.87$ & $<.001$ \\
PRISM-III & $19.28 \pm 10.28$ & $16.53 \pm 8.14$ & $28.97 \pm 11.26$ & $<0.001$ \\
pSOFA & $7.24 \pm 3.99$ & $9.06 \pm 3.57$ & $12.38 \pm 4.56$ & 0.001 \\
Glasgow coma scale & $10.66 \pm 4.46$ & $1.57 \pm 1.48$ & $2.21 \pm 1.86$ & 0.097 \\
Creatinine $(\mathrm{mg} / \mathrm{dl})$ & $0.97 \pm 0.89$ & $0.96 \pm 0.90$ & $1.00 \pm 0.87$ & 0.842 \\
Total bilirubin (mg/dl) & $2.47 \pm 6.42$ & $2.21 \pm 6.93$ & $3.38 \pm 4.15$ & 0.390 \\
Lactic acid $(\mathrm{mmol} / \mathrm{L})$ & $3.79 \pm 3.93$ & $2.79 \pm 2.73$ & $7.31 \pm 5.31$ & $<.001$ \\
CRP $(\mathrm{mg} / \mathrm{dl})$ & $11.85 \pm 11.78$ & $11.47 \pm 11.32$ & $13.26 \pm 13.45$ & 0.478 \\
BNP (pg/ml) & $607.86 \pm 960.81$ & $578.73 \pm 924.68$ & $1,450.20 \pm 1,613.22$ & 0.015 \\
Use of mechanical ventilator & $82(62.6)$ & $58(56.9)$ & $24(82.8)$ & 0.011 \\
Use of vasoactive inotropic agents & $51(38.9)$ & $35(34.3)$ & $16(55.2)$ & 0.042 \\
Use of renal replacement therapy & $36(27.5)$ & $27(26.5)$ & $9(31)$ & 0.627 \\
\hline
\end{tabular}

Values are presented as mean \pm standard deviation or number (\%).

PICU: pediatric intensive care unit; OPRISM-III: oncological pediatric risk of mortality-III; PRISM-III: pediatric risk of mortality-III; pSOFA: pediatric Sequential Organ Failure Assessment; CRP: C-reactive protein; BNP: B-type natriuretic peptide. 
Table 3. Multivariate logistic regression analysis for the prediction of PICU mortality

\begin{tabular}{|c|c|c|c|c|c|c|}
\hline \multirow{2}{*}{ Variable } & \multicolumn{2}{|c|}{ Multivariate (model 1) } & \multicolumn{2}{|c|}{ Multivariate (model 2) } & \multicolumn{2}{|c|}{ Multivariate (model 3) } \\
\hline & HR (95\% Cl) & P-value & HR (95\% Cl) & P-value & HR $(95 \% \mathrm{Cl})$ & P-value \\
\hline No. of HSCTs & $3.368(1.297-8.747)$ & 0.013 & 3.045 (1.190-7.792) & 0.02 & $3.532(1.435-8.678)$ & 0.006 \\
\hline Septic shock & $0.794(0.175-3.598)$ & 0.765 & $1.028(0.207-5.092)$ & 0.973 & $0.917(0.225-3.730)$ & 0.903 \\
\hline OPRISM-III & $1.142(1.080-1.208)$ & $<0.001$ & & & & \\
\hline PRISM-III & & & $1.148(1.082-1.218)$ & $<0.001$ & & \\
\hline pSOFA & & & & & $1.250(1.109-1.409)$ & $<0.001$ \\
\hline
\end{tabular}

PICU: pediatric intensive care unit; HR: hazard ratio; Cl: confidence incidence; HSCT, hematopoietic stem cell transplantation; OPRISM-III: oncological pediatric risk of mortality-III; PRISM-III: pediatric risk of mortality-III; pSOFA: pediatric Sequential Organ Failure Assessment.

with the 28-day mortality, and the AUC value of OPRISM-III score was the largest compared with other severity of illness scores (AUROC, 0.818; 95\% CI, 0.731-0.905) (Figure 1). Using the DeLong test, the AUROC value of OPRISM-III and PRISMIII were significantly larger than that of pSOFA. However, there were no significant differences between OPRISM-III and PRISM-III. Then, we calculated the cut-off value of each score by using the AUC and obtained appropriate cut-off values. The cut-off value of OPRISM-III was 21.5, PRISM-III was 19.5, and pSOFA was 11. All scoring systems showed significant differences with respect to the cut-off values associated with the 28day mortality in the Kaplan-Meier analysis (Figure 2).

\section{DISCUSSION}

Although there have been changes in conditioning regimen, immunosuppressive agents due to the complications after HSCT, the mortality that occurs after BMT is still high. According to the result of this study, when comparing the survivors and non-survivors, the number of HSCTs received, septic shock, use of inotropics and MV, severity of illness scores, serum lactic acid and BNP levels were associated with mortality in pediatric patients after HSCT. In multivariate analysis of 28-day mortality, the number of HSCTs done, OPRISM-III, PRISM-III, and pSOFA scores were the independent prognostic factors of 28-day mortality.

The number of HSCTs received and use of MV are already known predictors of mortality, based on previous studies $[10,11,13,18-21]$. The strength of our study was that the three scoring systems mentioned in each of the different studies are all significant predictors of mortality. Previous pediatric study, the OPRISM and PRISM-III were investigated for predicting mortality [22-27]. Another pediatric study reported that the difference between the maximum pSOFA and admission pSOFA scores was associated with the PICU mortality [28].

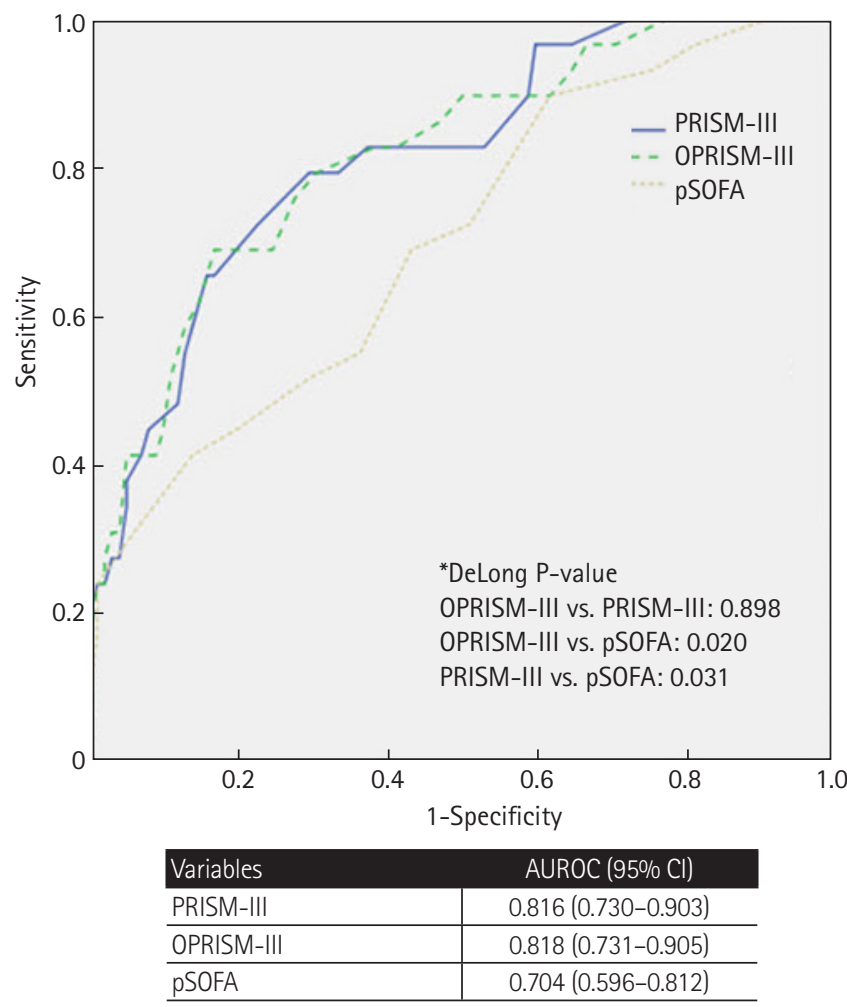

Figure 1. Receiver operating characteristics (ROC) curve and result of DeLong test between the area under the curve value of each scoring system. PRISM-III: pediatric risk of mortality-III; OPRISM-III: oncological pediatric risk of mortality-III; pSOFA: pediatric Sequential Organ Failure Assessment; AUROC: area under the receiver operating characteristics; $\mathrm{Cl}$ : conficdence interval.

Our study differed from the previous pediatric study in that we evaluated the pSOFA score, a useful evaluation tool in recent pediatric critical care, together with OPRISM-III and PRISM-III on PICU admission. Therefore, three scoring systems were all useful tool to predict mortality of critically ill pediatric patients received BMT according to our study.

Previous studies showed that septic shock, use of vasoactive inotropes, and serum lactic acid were good predictors 


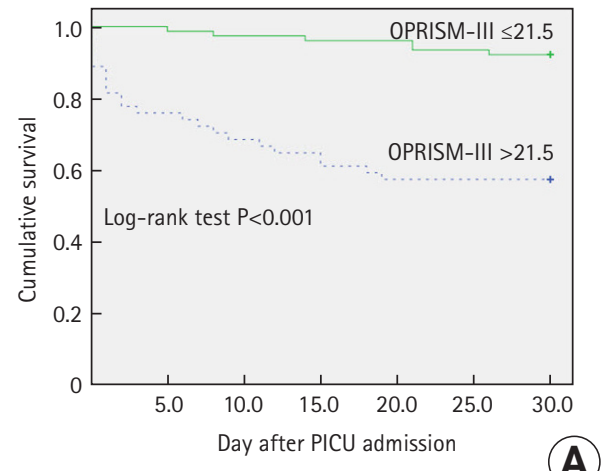

(A)
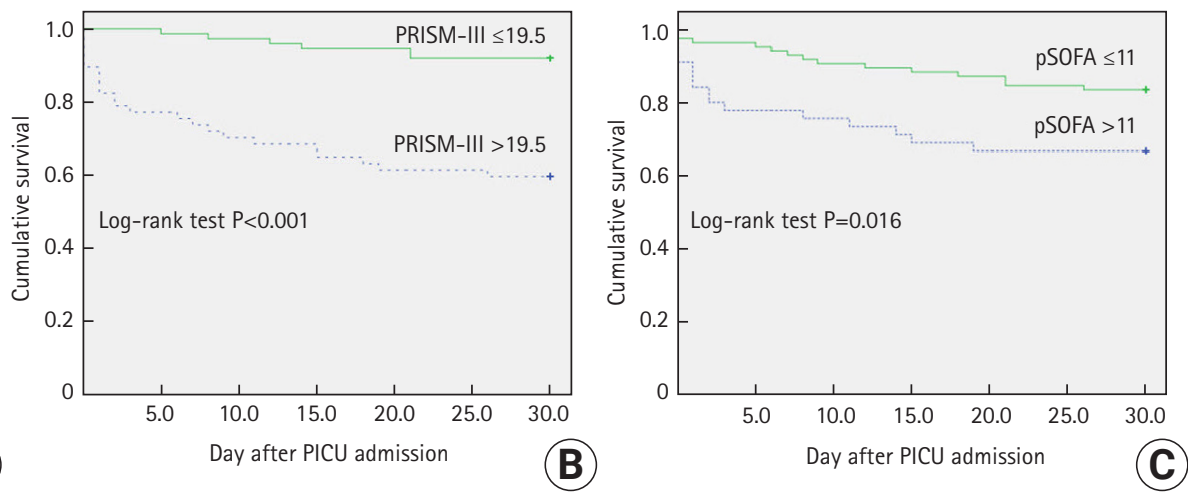

Figure 2. Kaplan-Meier analysis of oncological pediatric risk of mortality-III (OPRISM-III; A), pediatric risk of mortality-III (PRISM-III; B) and pediatric Sequential Organ Failure Assessment (pSOFA; C). All of these three scoring systems have significant difference in 28-day mortality. PICU: pediatric intensive care unit.

between survivors and non-survivors [10,18,23,29]. However, the GCS, creatinine, total bilirubin known mortality predictors in hildren after HSCT were not associated with mortality in our study $[19,22,23,27,28,30,31]$. When each organ failure is separately investigated, no correlation with the probability of mortality was seen in our study. However, the severity of illness scores at PICU admission, such as the pSOFA score, which includes the GCS score, creatinine, total bilirubin, that showed perfect discriminatory power for the evaluation of multi organ function adjusted for age were significantly higher among the non-survivors [16].

Previous studies have shown that septic shock to be a significant predictor of outcome in HSCT recipients admitted to the ICU $[32,33]$. In our study, septic shock was not significant factor by using multivariate logistic regression analysis. Because, most septic shock patients had effective response on early fluid therapy and vasopressor administration. Although septic shock is associated with an overall severe course, rapid recovery of specific organ function has been noted due to recent advances and improvements in the management of septic shock in cancer patients $[34,35]$. Early involvement in septic shock treatment represents that it had less effect on mortality than other organ complications. Rather, multi organ dysfunction on the first day after PICU admission were found to be more important than presence of septic shock at PICU admission.

Heart failure is a known complication of HSCT because of the use of cardiotoxic drugs post-transplantation, notably cyclophosphamide and anthracyclines $[36,37]$. Therefore, physicians often use BNP to monitor the cardiotoxic effects of medications after HSCT [38]. Although BNP may be a useful predictor of cardiac dysfunction after HSCT, it is not superior to other factors in predicting mortality. Even though we compensated for age-based creatinine levels, it has been confirmed that there is no association between creatinine level and BNP. In terms of vasopressors, several studies have shown that the use of vasopressors had a negative impact on survival in univariate analysis but was not significantly associated with mortality in multivariate analysis when compared with the severity of illness scores, such as APACHE II, SOFA, and OPRISM scores $[11,21,23]$. In our study, the severity of illness scores, such as PRISM-III and pSOFA scores, which included the systolic blood pressure (SBP) or MAP and the amount of vasoactive infusion as variables, were the independent prognostic factors of the 28-day mortality compared to the use of vasoactive inotropes. This result showed that the amount of inotropes and MAP or SBP before starting inotropes are more important factors for predicting the 28-day mortality in the PICU than the use of inotropes

There are some limitations of this study. This study was a retrospective single-center study, investigating only HSCT patients. Thus, the results cannot be generalized to all hemato-oncologic patients. It is necessary to study larger cohorts of HSCT patients from multiple centers. In conclusion, this study investigated the patients admitted to the PICU after HSCT at a single center. We found that the number of HSCTs received, use of MV, and the severity of illness scores (OPRISMIII, PRISM-III, and pSOFA scores) were the strong prognostic factors for PICU mortality in the critically-ill pediatric patients after HSCT.

\section{CONFLICT OF INTEREST}

No potential conflict of interest relevant to this article was reported. 


\section{ORCID}

$\begin{array}{ll}\text { Da Hyun Kim } & \text { https://orcid.org/0000-0002-8588-7848 } \\ \text { Eun Ju Ha } & \text { https://orcid.org/0000-0002-2866-3848 } \\ \text { Seong Jong Park } & \text { https://orcid.org/0000-0003-0250-2381 } \\ \text { Kyung-Nam Koh } & \text { https://orcid.org/0000-0002-6376-672X } \\ \text { Hyery Kim } & \text { https://orcid.org/0000-0003-2852-6832 } \\ \text { Ho Joon Im } & \text { https://orcid.org/0000-0001-8799-4068 } \\ \text { Won Kyoung Jhang } & \text { https://orcid.org/0000-0003-2309-0494 }\end{array}$

\section{AUTHOR CONTRIBUTIONS}

Conceptualization: DHK, SJP, KNK, HK, HJI, WKJ. Formal analysis: DHK, WKJ, SJP. Methodology: DHK, WKJ, SJP, HJI. Data curation: DHK, EJH. Writing-original draft: DHK, WKJ. Writing-review \& editing: SJP, WKJ.

\section{REFERENCES}

1. Savaşan S, Abella EM. Current issues in pediatric stem cell transplantation. Clin Lab Med 2005;25:519-40.

2. Gratwohl A, Baldomero H, Aljurf M, Pasquini MC, Bouzas LF, Yoshimi A, et al. Hematopoietic stem cell transplantation: a global perspective. JAMA 2010;303:1617-24.

3. Appelbaum FR. Hematopoietic-cell transplantation at 50. N Engl J Med 2007;357:1472-5.

4. Copelan EA. Hematopoietic stem-cell transplantation. N Engl J Med 2006;354:1813-26.

5. Oudin C, Chevallier P, Furst S, Guillaume T, El Cheikh J, Delaunay J, et al. Reduced-toxicity conditioning prior to allogeneic stem cell transplantation improves outcome in patients with myeloid malignancies. Haematologica 2014;99:1762-8.

6. Bacigalupo A, Ballen K, Rizzo D, Giralt S, Lazarus H, Ho V, et al. Defining the intensity of conditioning regimens: working definitions. Biol Blood Marrow Transplant 2009;15:1628-33.

7. Passweg JR, Baldomero H, Peters C, Gaspar HB, Cesaro S, Dreger P, et al. Hematopoietic SCT in Europe: data and trends in 2012 with special consideration of pediatric transplantation. Bone Marrow Transplant 2014;49:744-50.

8. Gooley TA, Chien JW, Pergam SA, Hingorani S, Sorror ML, Boeckh M, et al. Reduced mortality after allogeneic hematopoietic-cell transplantation. N Engl J Med 2010;363:2091-101.

9. Azoulay E, Afessa B. The intensive care support of patients with malignancy: do everything that can be done. Intensive Care Med 2006;32:3-5.

10. Pène F, Aubron C, Azoulay E, Blot F, Thiéry G, Raynard B, et al.
Outcome of critically ill allogeneic hematopoietic stem-cell transplantation recipients: a reappraisal of indications for organ failure supports. J Clin Oncol 2006;24:643-9.

11. Platon L, Amigues L, Ceballos P, Fegueux N, Daubin D, Besnard $\mathrm{N}$, et al. A reappraisal of ICU and long-term outcome of allogeneic hematopoietic stem cell transplantation patients and reassessment of prognosis factors: results of a 5-year cohort study (2009-2013). Bone Marrow Transplant 2016;51:256-61.

12. Benz R, Schanz U, Maggiorini M, Seebach JD, Stussi G. Risk factors for ICU admission and ICU survival after allogeneic hematopoietic SCT. Bone Marrow Transplant 2014;49:62-5.

13. Saillard C, Blaise D, Mokart D. Critically ill allogeneic hematopoietic stem cell transplantation patients in the intensive care unit: reappraisal of actual prognosis. Bone Marrow Transplant 2016;51:1050-61.

14. Saillard C, Darmon M, Bisbal M, Sannini A, Chow-Chine L, Faucher M, et al. Critically ill allogenic HSCT patients in the intensive care unit: a systematic review and meta-analysis of prognostic factors of mortality. Bone Marrow Transplant 2018;53:1233-41.

15. Pollack MM, Patel KM, Ruttimann UE. PRISM III: an updated pediatric risk of mortality score. Crit Care Med 1996;24:743-52.

16. Matics TJ, Sanchez-Pinto LN. Adaptation and validation of a pediatric sequential organ failure assessment score and evaluation of the sepsis-3 definitions in critically ill children. JAMA Pediatr 2017; 171:e172352.

17. Schneider DT, Lemburg P, Sprock I, Heying R, Göbel U, Nürnberger W. Introduction of the oncological pediatric risk of mortality score (O-PRISM) for ICU support following stem cell transplantation in children. Bone Marrow Transplant 2000;25:1079-86.

18. Soubani AO, Kseibi E, Bander JJ, Klein JL, Khanchandani G, Ahmed HP, et al. Outcome and prognostic factors of hematopoietic stem cell transplantation recipients admitted to a medical ICU. Chest 2004;126:1604-11.

19. Jacobe SJ, Hassan A, Veys P, Mok Q. Outcome of children requiring admission to an intensive care unit after bone marrow transplantation. Crit Care Med 2003;31:1299-305.

20. Keenan HT, Bratton SL, Martin LD, Crawford SW, Weiss NS. Outcome of children who require mechanical ventilatory support after bone marrow transplantation. Crit Care Med 2000;28:830-5.

21. Mokart D, Granata A, Crocchiolo R, Sannini A, Chow-Chine L, Brun JP, et al. Allogeneic hematopoietic stem cell transplantation after reduced intensity conditioning regimen: outcomes of patients admitted to intensive care unit. J Crit Care 
2015;30:1107-13.

22. Choi HS, Lee EJ, Lee JW, Jang PS, Chung NG, Cho B, et al. Prediction of Prognosis for children cared in intensive care unit (ICU) after hematopoietic stem cell transplantation (HSCT). Korean J Crit Care Med 2011;26:226-31.

23. González-Vicent M, Marín C, Madero L, Sevilla J, Díaz MA. Risk score for pediatric intensive care unit admission in children undergoing hematopoietic stem cell transplantation and analysis of predictive factors for survival. J Pediatr Hematol Oncol 2005;27:526-31.

24. Cheuk DK, Ha SY, Lee SL, Chan GC, Tsoi NS, Lau YL. Prognostic factors in children requiring admission to an intensive care unit after hematopoietic stem cell transplant. Hematol Oncol 2004;22:1-9.

25. Tomaske M, Bosk A, Eyrich M, Bader P, Niethammer D. Risks of mortality in children admitted to the paediatric intensive care unit after haematopoietic stem cell transplantation. Br J Haematol 2003;121:886-91.

26. Zinter MS, Logan BR, Fretham C, Sapru A, Abraham A, Aljurf $\mathrm{MD}$, et al. Comprehensive prognostication in critically ill pediatric hematopoietic cell transplant patients: results from merging the center for international blood and marrow transplant research (CIBMTR) and virtual pediatric systems (VPS) registries. Biol Blood Marrow Transplant 2020;26:333-42.

27. Lamas A, Otheo E, Ros P, Vázquez JL, Maldonado MS, Muñoz A, et al. Prognosis of child recipients of hematopoietic stem cell transplantation requiring intensive care. Intensive Care Med 2003;29:91-6.

28. Kwon R, Koutsogiannaki S, Staffa SJ, Yuki K. The outcomes of pediatric hematopoietic stem cell transplantation recipients requiring intensive care unit admission: a single center experience. Transl Perioper Pain Med 2019;6:75-80.

29. Kumar G, Ahmad S, Taneja A, Patel J, Guddati AK, Nanchal R. Milwaukee initiative in critical care outcomes research group of investigators: severe sepsis in hematopoietic stem cell transplant recipients. Transl Perioper Pain Med 2019;6:75-80.
30. Fernández-García M, Gonzalez-Vicent M, Mastro-Martinez I, Serrano A, Diaz MA. Intensive care unit admissions among children after hematopoietic stem cell transplantation: incidence, outcome, and prognostic factors. J Pediatr Hematol Oncol 2015;37:529-35.

31. Schneider DT, Cho J, Laws HJ, Dilloo D, Göbel U, Nürnberger W. Serial evaluation of the oncological pediatric risk of mortality (O-PRISM) score following allogeneic bone marrow transplantation in children. Bone Marrow Transplant 2002;29:383-9.

32. Torrecilla C, Cortés JL, Chamorro C, Rubio JJ, Galdos P, Dominguez de Villota E. Prognostic assessment of the acute complications of bone marrow transplantation requiring intensive therapy. Intensive Care Med 1988;14:393-8.

33. Staudinger T, Stoiser B, Müllner M, Locker GJ, Laczika K, Knapp $\mathrm{S}$, et al. Outcome and prognostic factors in critically ill cancer patients admitted to the intensive care unit. Crit Care Med 2000;28:1322-8.

34. Pène F, Percheron S, Lemiale V, Viallon V, Claessens YE, Marqué S, et al. Temporal changes in management and outcome of septic shock in patients with malignancies in the intensive care unit. Crit Care Med 2008;36:690-6.

35. Zuber B, Tran TC, Aegerter P, Grimaldi D, Charpentier J, Guidet B, et al. Impact of case volume on survival of septic shock in patients with malignancies. Crit Care Med 2012;40:55-62.

36. McGowan JV, Chung R, Maulik A, Piotrowska I, Walker JM, Yellon DM. Anthracycline chemotherapy and cardiotoxicity. Cardiovasc Drugs Ther 2017;31:63-75.

37. Dhesi S, Chu MP, Blevins G, Paterson I, Larratt L, Oudit GY, et al. Cyclophosphamide-induced cardiomyopathy: a case report, review, and recommendations for management. J Investig Med High Impact Case Rep 2013;1:2324709613480346.

38. Snowden JA, Hill GR, Hunt P, Carnoutsos S, Spearing RL, Espiner E, et al. Assessment of cardiotoxicity during haemopoietic stem cell transplantation with plasma brain natriuretic peptide. Bone Marrow Transplant 2000;26:309-13. 